\title{
Obituary
}

\section{Dr Stanley Robbins}

Laboratory Investigation (2004) 84, 393. doi:10.1038/labinvest.3700067

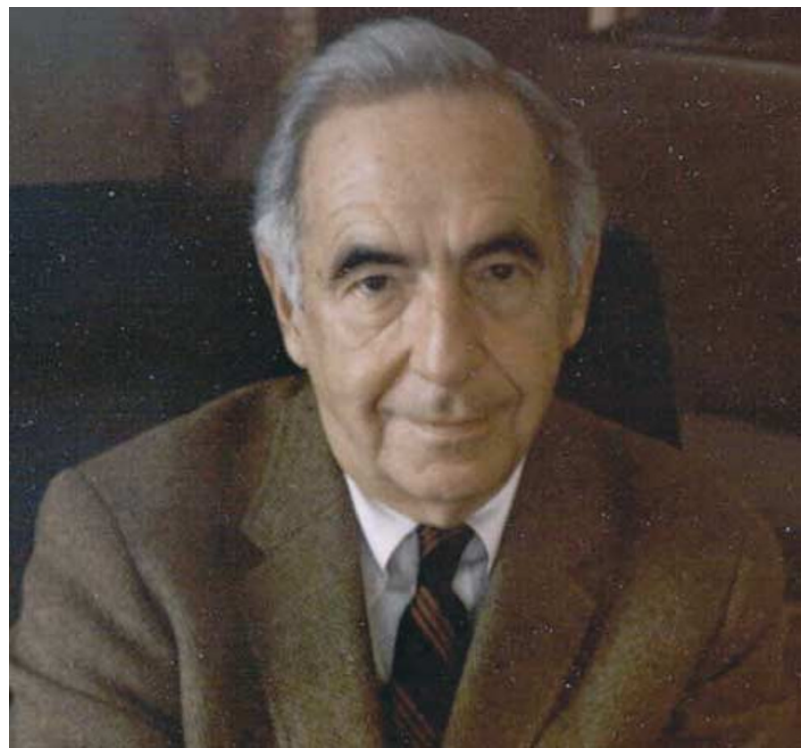

Dr Stanley L Robbins, one of the great pathologists of the 20th century, died on Tuesday, October 7, 2003 at the age of 88 years. This journal notes his passing with respect and honor, as he touched the lives of all who grew up to love and practice pathology in the past 45 years. Dr Robbins revolutionized the concepts of teaching pathology, by bringing morbid anatomy alive as a medical discipline. Born in Portland, Maine, in 1915, Dr Robbins graduated at the top of his class from Brookline High School in Brookline, Massachusetts. He went on to the Massachusetts Institute of Technology and Tufts Medical School, delivering the valedictory address at both schools upon graduation. After training at Boston City Hospital, Dr Robbins went on to teach at Boston University, Harvard, and Tufts Medical Schools. He became Director of Boston University's Mallory Institute of Pathology and Chairman of that school's Department of Pathology in 1965, a position he held until 1980. Upon his retirement from these positions, he accepted a post as Senior Pathologist at the Brigham and Women's Hospital in Boston. He continued to teach medical school students and pathologists-in-training for many years to follow. Without question, Dr Robbins' legacy is his teaching and his textbooks of Pathology. His first textbook, Pathology, was published in 1957 and went through three editions. It is noteworthy that despite the fact that the original 'Robbins', simply called Pathology, was a great success in its first three editions, Robbins took the unusual step of completely rewriting the fourth edition of his book as the first edition of Pathologic Basis of Disease. Both the new title and the text reflected increasing emphasis on disease mechanisms. Few successful authors would have taken such a risk, but Robbins had a visceral sense and deep conviction that pathology without pathogenesis was sterile and that the time had come to proclaim this in the title of the book. Thus, a greatly expanded Pathologic Basis of Disease was first published in 1974, and is now entering into its seventh edition as Robbins' Pathologic Basis of Disease (2004). It is fair to say that every American physician trained in the last four decades of the 20th century can mark their education by which edition of Robbins they read. For me, it was the second edition for medical school, and the third edition for pathology residency. To quote from the preface to the first edition, this textbook delves into the 'whys' and 'wherefores' of disease, not just the 'whats'. As a result, Robbins explains the mechanisms that underlie clinical illness, so that the connection between pathology and the care of patients is immediately tangible. His other book, Basic Pathology (affectionately called 'Baby Robbins') was born in 1971 in response to the need for a more concise text that focused on the 'core' pathology curriculum. Together, the two texts have been translated into more than 13 languages, including (the likes of) Serbian, Chinese, Turkish, and Indonesian! Dr Robbins also was a consummate editor, holding a growing number of coauthors and contributors to his high standards. For my verbose style, one of his axioms was, 'There is no sentence two words or longer that cannot be simplified and shortened.' His office also exemplified efficient scholarship. Filing cabinets would grow to bursting over a 3-year period, and upon publication of each new edition of Robbins, the cabinets would be emptied to fill anew with the breadth of medical knowledge for the following edition. During his long career, Dr Robbins also made key contributions in research, helping to develop the frog pregnancy test. This became the standard test for pregnancy worldwide before the advent of the rabbit pregnancy test. $\mathrm{He}$ also conducted early research into coronary artery disease. Dr Robbins is a recipient of the United States and Canadian Academy of Pathology 1991 Distinguished Pathologist Award and in 1992, the Gold Headed Cane Award of the American Society of Investigative Pathology.

We will treasure his memory.

James M Crawford Editor-in-Chief, Laboratory Investigation 